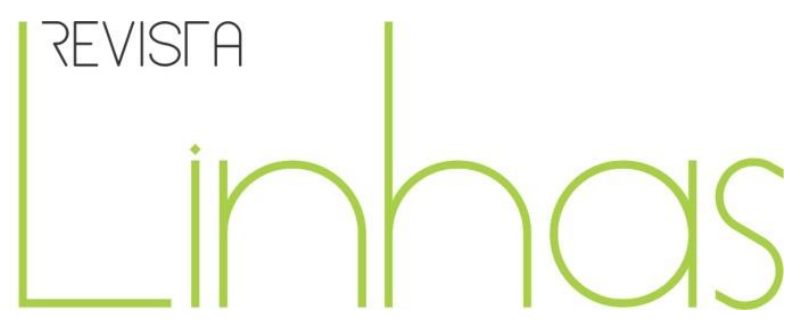

\title{
A inclusão digital de crianças com múltiplas deficiências na escola
}

\section{Resumo}

Nos artefatos tecnológicos estão subjacentes visões de mundo, linguagens, conhecimentos, bem como questões objetivas em construção, que surgem como alternativas para aprender a pensar as demandas da comunidade escolar e digital. O presente ensaio busca compreender a cultura da escola, através de uma pesquisa etnográfica, apresentando as aporias enfrentadas no cotidiano educativo em termos do uso de tecnologias digitais por crianças com múltiplas deficiências. Na atualidade, as tecnologias digitais têm demonstrado a possibilidade de uma nova perspectiva educacional enquanto ferramentas no processo de ensino e de integração das diferenças na escola regular, visto que no mundo infantil a conexão digital é incorporada como forma de comunicação e intercâmbio, superando os isolamentos em diferentes contextos. Mas, será que os recursos tecnológicos podem motivar processos de ensino e de aprendizagem inclusivos, facilitando a transformação das atividades pedagógicas reprodutivas e de segregação por novas compreensões nas diferenças que os enfoques tecnológicos colocam à práxis? Neste sentido, o trabalho gira em torno de problemas de investigação apontados e identificados na cultura da escola, considerando os artefatos digitais na realidade dos educandos com deficiências. A partir do contexto apresentado, o trabalho conclui que o acesso às tecnologias digitais de informação e comunicação (TDIC) e à tecnologia assistiva (TA) torna-se relevante para viabilizar a inclusão humana, tecnológica, educacional e social de educandos com múltiplas deficiências, tanto para a melhoria das condições de relacionamento social com as limitações sentidas pelos sujeitos, mas, sobretudo, para o reconhecimento inclusivo nos diferentes espaços e tempos da formação socializada.

Palavras-chave: Inclusão Digital. Inclusão Escolar. Múltiplas Deficiências.

\author{
Carla Elisandra Oliveira Carvalho \\ Universidade La Salle - \\ UNILASALLE - Canoas/RS - Brasil \\ angercarla@gmail.com
}

\section{Adilson Cristiano Habowski}

Universidade La Salle -

UNILASALLE - Canoas/RS - Brasil adilsonhabowski@hotmail.com

\section{Elaine Conte}

Universidade La Salle -

UNILASALLE - Canoas/RS - Brasil elaine.conte@unilasalle.edu.br

\section{Para citar este artigo:}

CARVALHO, Carla Elisandra Oliveira; HABOWSKI, Adilson Cristiano; CONTE, Elaine. A inclusão digital de crianças com múltiplas deficiências na escola. Revista Linhas. Florianópolis, v. 20, n. 42, p. 153-176, jan./abr. 2019. 


\title{
The digital inclusion of children with multiple deficiencies in school
}

\begin{abstract}
In the technological artifacts are underlying world views, languages, knowledge, as well as objective issues in construction, that appear as alternatives to learn to think the demands of the school and digital community. This essay tries to understand the culture of the school through an ethnographic research, presenting the aporias faced in the daily education in terms of the use of digital technologies by children with multiple disabilities. At present, digital technologies have demonstrated the possibility of a new educational perspective as tools in the process of teaching and integrating differences in the regular school, since in the children's world the digital connection is incorporated as a form of communication and exchange, overcoming the isolation in different contexts. But can technological resources motivate inclusive teaching and learning processes, facilitating the transformation of reproductive pedagogical activities and segregation by new understandings of the differences that technological approaches pose to praxis? In this sense, the work revolves around research problems identified and identified in the school culture, considering the digital artifacts in the reality of students with disabilities. From the context presented, the study concludes that access to digital information and communication technologies (TDIC) and assistive technology (TA) becomes relevant to enable the human, technological, educational and social inclusion of students with multiple disabilities, both for the improvement of the conditions of social relationship with the limitations felt by the subjects, but, above all, for the inclusive recognition in the different spaces and times of the socialized formation.
\end{abstract}

Keywords: Digital Inclusion. School Inclusion. Multiple Disabilities. 


\section{Considerações iniciais}

Se somos diferentes em termos de DNA e aparência (na quase totalidade), parece que somos iguais em princípios básicos, em potência existencial, em termos de singularidade nas ações diante do mundo (das contingências e das metamorfoses), guardando semelhanças inclusive em necessidades biológicas. Na atualidade, as tecnologias digitais surgem como possibilidades ao desenvolvimento de um novo paradigma educacional, pois percebemos que desde a tenra idade, as crianças estão em contato com as tecnologias e esse fator pode trazer consigo mudanças nos modos de comunicação e de interação na sala de aula. Os recursos tecnológicos usados na educação devem caminhar no sentido de buscar o aprimoramento e reconciliação com os processos de ensino e de aprendizagem, movimentando antigas perspectivas e propiciando atividades pedagógicas diferenciadas e em constante renovação. Tal realidade requer dos profissionais da área uma práxis contextualizada e interconectada com a realidade concreta dos estudantes. Tudo indica que tanto adultos quanto crianças com deficiências têm receio em usar as tecnologias digitais, muitas vezes, pela falta de incentivo e de pessoas dispostas a ensinar e impulsionar as dimensões cognitivas, desacomodando o aprender e o pensar por meio das experiências tecnológicas. Percebemos nos meios tecnológicos grandes auxiliares da educação quando não são tomados com fins em si, de forma neutra, formal, mas como dispositivos que ajudam a movimentar o pensamento e a reconstruir conhecimentos no mundo.

Diante disso, indagamos: com a obrigatoriedade de inclusão nas escolas das crianças com múltiplas deficências, como ir além de um modelo de escola de cuidado assistencial, dadas as graves deficiências, para que sejam incluídas nas salas de aula as crianças que não falam e precisam de um mediador para interagir? Será que os artefatos digitais nesse cenário permitem pensar a educação através da mobilidade digital das diferenças, tendo os professores como articuladores das preocupações acerca da alteridade, do pertencimento, das vivências com os diferentes jeitos, tempos, gostos e hábitos dos estudantes? Talvez, seria a oportunidade de aproveitar essas tecnologias e usá-las pedagogicamente e de forma reflexiva. Assim, o estudo identifica as tecnologias utilizadas pelos professores em sala de aula, verificando se elas atendem aos contextos inclusivos das crianças com múltiplas deficiências. Para isso, se faz necessário 
compreender os sentidos que as tecnologias representam e mobilizam no processo de inclusão das crianças no contexto escolar, identificando se os equipamentos tecnológicos nas escolas estão sendo aproveitados para atender as crianças com deficiências, bem como apresentar as visões dos professores acerca das tecnologias no cotidiano escolar.

Estamos alicerçados numa perspectiva hermenêutica que pode ser entendida como a maneira pela qual interpretamos algo no mundo, enquanto finalidade de formarse e educar-se conforme as necessidades contextuais. A interpretação decorre de um texto, de um gesto, de um símbolo, de uma atitude, de uma palavra de abertura e relação com o outro, que possui a capacidade de comunicar-se. A hermenêutica busca uma reflexão e uma compreensão sobre aquilo que vemos, lemos, vivenciamos, criando uma cultura imersa em diferentes tradições e experiências compartilhadas. Implica também na forma como realizamos o movimento para nos (re)conhecer, a partir das experiências no mundo, ou seja, na medida em que interpretamos algo, relacionamos diretamente com a visão de mundo que temos, oriunda de nossas experiências. Sendo assim, tematizar a compreensão como modo fundador da existência humana lança questões críticas sobre o que é educar, aprender, compreender, pesquisar e dialogar, para dar conta da singularidade da vida humana.

Quando a experiência hermenêutica enseja outras possibilidades interpretativas, a educação como se desprende das amarras conceituais provenientes da visão científico-objetivista e da tradição metafísica, passa então a produzir os efeitos benéficos da abertura de horizontes e da ampliação da base epistemológica. Assim, a possibilidade compreensiva da hermenêutica desfaz o prejudicial equívoco que há entre educação compensatória e educação no sentido amplo da formação. (HERMANN, 2003, p. 9-10)

Acreditamos, assim, que nossas reflexões sempre nos levam a novas compreensões da situação atual que ainda se apresenta como um desafio. Por tudo isso, para que a compreensão ocorra, é preciso que aquilo que tentamos interpretar faça sentido para nós mesmos. Sobre esse enfoque, realizamos uma pesquisa de caráter etnográfico, visando descrever a cultura da escola em relação ao entendimento das tecnologias, como também as incorporações desses artefatos nas atividades pedagógicas com crianças de múltiplas deficiências. 


\section{A legislação brasileira e a inclusão digital das diferenças}

Percebe-se que o acesso à tecnologia assistiva ${ }^{1}$ torna-se um fator importante para viabilizar a inclusão social e educacional de pessoas com múltiplas deficiências, principalmente para os mais propensos a sofrerem socialmente com as próprias limitações. Para tanto, "a aplicação da Tecnologia Assistiva na educação vai além de simplesmente auxiliar o aluno a 'fazer' tarefas pretendidas. Nela, encontramos meios de o aluno ser e atuar de forma construtiva no seu processo de desenvolvimento" (BERSCH; TONOLLI, 2006, p. 92). Sob esse enfoque, é necessário rever constantemente o impacto da TA na educação para a existência desses espaços e linguagens nas escolas rumo à inclusão que leva a pensar sobre a mobilidade social. No entanto, nas escolas, muitas reclamações surgem por parte dos professores sobre as ambiguidades e as contradições das tecnologias na educação. Nota-se, por exemplo, que as salas de recursos multifuncionais (SRM) acabam sendo espaços que não promovem os entrelaçamentos sociais, pois frequentemente os estudantes que necessitam desses recursos são retirados dos espaços de convivência dos colegas para ficarem isolados nessas salas com a supervisão de um responsável, nem sempre um educador especial. Na preocupação de estabeler uma educação de qualidade e inclusiva, Levy e Facion (2009, p. 147) destacam que "é fundamental a participação do professor. O êxito de sua atividade é determinante pelas suas condições de trabalho, formação, competência pedagógica, habilidades e avaliações periódicas das estratégias metodológicas utilizadas".

Mas, de que forma podemos disponibilizar às pessoas com múltiplas deficiências (físicas, cognitivas, psicossociais) as possibilidades para um desenvolvimento da globalidade humana, tornando as tecnologias instrumentos de criação e inovação do conhecimento, um direito de inclusão social e democrática dos saberes? A democratização da cultura por meio da formação permanente de modos de pensar pela via da TA, por exemplo, pode abrir novos mundos aos sujeitos que têm dificuldades físicas, de relacionamento e convivência social, para que estabeleçam contatos e elos,

\footnotetext{
1 "Tecnologia Assistiva é uma área do conhecimento, de característica interdisciplinar, que engloba produtos, recursos, metodologias, estratégias, práticas e serviços que objetivam promover a funcionalidade, relacionada à atividade e participação de pessoas com deficiência, incapacidades ou mobilidade reduzida, visando sua autonomia, independência, qualidade de vida e inclusão social" (BRASIL, 2007a, p. 03). Eustat (1999, s/n) afirma que "um modelo de formação e treino em tecnologias de apoio deve ser baseado num modelo de desenvolvimento humano que tenha em consideração os problemas que as pessoas com deficiência apresentam quando tentam adaptar-se a um ambiente adverso".
} 
aprimorando conhecimentos, encontrando formas alternativas de diversão, relações afetivas, de vínculos sociais e de participação cidadã. A universalização do acesso à tecnologia assistiva é uma condição para a inserção de pessoas com limitações ou dificuldades para participar da vida democrática, mas é preciso reconhecer as enganações inscritas em interações institucionalizadas para conhecer os limites da realidade.

Historicamente, podemos constatar inúmeros relatos de exclusão de pessoas com deficiências, que eram tratadas com diferentes adjetivos depreciativos, tais como: aleijados, enjeitados, débil mental, mancos, cegos, mongolóides, surdos-mudos. Todavia, tal como ocorria no continente europeu, a quase totalidade dessas informações está diluída nas menções relativas às populações menos favorecidas. No Brasil, a pessoa deficiente foi maltratada por séculos, sendo relegada à categoria dos miseráveis e afetada pela exclusão do convívio social. As transformações do século XX possibilitaram novos estudos na área medicinal, trazendo questionamentos sobre os meios necessários às pessoas com deficiências terem uma vida melhor, com relação ao direito de participar da esfera social e educacional.

O eixo das ações que conduzem à inclusão tem por base uma filosofia que reconhece e valoriza a diversidade na vida em sociedade. Nesse sentido, a ideia de inclusão visa assegurar o acesso das pessoas a todas as oportunidades de convívio social, enquanto sujeitos de possibilidades, integrando e contextualizando as peculiaridades de cada sujeito e grupo social. Observa-se que nos inúmeros fóruns sobre educação inclusiva têm se incrementado ações e políticas referentes à proteção das formas de interação que garantem o exercício pleno e equitativo de todos, com ou sem deficiência. Por isso, adotam-se políticas públicas de promoção e respeito à dignidade da pessoa humana em situação de risco.

Sob esse prisma, a legislação educacional tem por base a Constituição Federal, no que diz respeito à educação inclusiva, cujo princípio da igualdade é expresso no caput do artigo $5^{\circ}$, nos seguintes termos: "todos são iguais perante a lei, sem distinção de qualquer natureza, garantindo-se aos brasileiros e aos estrangeiros, residentes no País, a inviolabilidade do direito à vida, à liberdade, à igualdade, à segurança e à propriedade". A Constituição Federal brasileira tem por propósito uma visão de criança como pessoa de direitos. Esses direitos foram regulamentados no Estatuto da Criança e do Adolescente 
(Lei Federal n. 8.969/90), explicitando a concepção de criança cidadã, "que significa entendê-las como sujeitos de direitos, que merecem proteção integral, porque se encontram em condições especiais de desenvolvimento" (FERREIRA, 2006, p. 38).

De acordo com a ideia constitucional, a Política Nacional de Educação Especial, na perspectiva da educação inclusiva, buscou enfatizar o desenvolvimento integral dos estudantes com múltiplas deficiências. A Política Nacional de Educação promove “o acesso, a participação e a aprendizagem dos alunos com deficiência, transtornos globais do desenvolvimento e altas habilidades/superdotação nas escolas regulares, orientando os sistemas de ensino para promover respostas às necessidades educacionais especiais" (BRASIL, 2007, p. 65). Este documento busca ainda garantir:

a) Transversalidade da educação especial desde a educação infantil até a educação superior; b) Atendimento educacional especializado; c) Continuidade da escolarização nos níveis mais elevados do ensino; d) Formação de professores para o atendimento educacional especializado e demais profissionais da educação para a inclusão escolar; e) Participação da família e da comunidade; f) Acessibilidade urbanística, arquitetônica, nos mobiliários e equipamentos, nos transportes, na comunicação e informação; e g) Articulação intersetorial na implementação das políticas públicas. (BRASIL, 2007, p. 67)

Nesse contexto, Ferreira (2006) revela ser a inclusão um termo muito utilizado como sinônimo para a integração de estudantes com deficiência no ensino regular, uma perpetuação da vinculação do conceito com a educação especial. Todavia, os pesquisadores também dizem que a inclusão não é somente de crianças com deficiências e sim de crianças, jovens e adultos que sofrem qualquer tipo de exclusão educacional, seja pela falta de oportunidades para participar das atividades escolares, ou quando são expulsos e suspensos (por razões obscuras), quando não têm acesso à escolarização e permanecem fora da escola e da participação da vida social. Mas, como incluir em uma sala de aula com 30 a 40 estudantes as singularidades e as diferenças daqueles que não conseguem se comunicar ou se mover, sem segregar? Embora a inclusão digital esteja mesclada aos esforços de levar às sociedades contemporâneas um meio de se obter os conhecimentos para expressão das linguagens e produções humanas, a atenção às múltiplas deficiências nos espaços escolares precisa ser ampliada com novas leituras e 
interações, principalmente pelos professores, tendo em vista o círculo dinâmico das necessidades emergentes dos fenômenos biológicos e culturais no mundo.

$\mathrm{Na}$ perspectiva de Sampaio (2001), existem duas formas de inclusão digital, a restrita e a ampliada. Na restrita, a ideia é de destacar o adestramento dos cidadãos para a utilização dos computadores e de aplicativos, tal como editores de texto, planilhas eletrônicas, acesso à internet para serviços governamentais e navegação na rede virtual ${ }^{2}$ (na qualidade do leitor). Na inclusão ampliada, busca-se a condição necessária para a afirmação de uma cidadania ativa pelos processos educativos e pedagógicos. Ela é capaz de motivar a cidadania para a participação como interlocutora e não só receptora na construção de políticas públicas. A inclusão digital em rede expressa a participação ativa dos sujeitos com capacidade não apenas de usar o artefato, mas de renovar conhecimentos, de conviver e criar laços que promovam a interlocução das diferentes culturas no ciberespaço. Acredita-se na necessidade de formar sujeitos capazes de se apropriar das oportunidades tecnológicas, para a concretização de uma formação coletiva e democrática, que se dá no contínuo esforço para uma cidadania global. Por sua vez, o aspecto significativo de inclusão digital abarca a alfabetização digital, como um conceito mais abrangente, em que o sujeito é capacitado para ações ligadas à cidadania participativa e ao papel crítico na esfera pública. Todavia, observa-se que a alfabetização digital está vinculada a outras formas de alfabetização, quais sejam, da língua, dos números, da ciência, da expressão corporal.

A inclusão digital precisa priorizar diferentes metodologias para ir além da linguagem computacional, colocando ênfase no conhecimento, cujo significado possa ser potencializado nas situações reais vividas. Além disso, a inclusão digital é incessante, pois implica na estimulação e na busca constante de conhecimentos, de forma interdependente e autônoma, na perspectiva de continuar aprendendo ao longo da vida e não apenas enquanto estão nas escolas. Tal observação revela a oportunidade da inclusão digital ir além da prática pedagógica, para assumir uma dimensão de inclusão

\footnotetext{
${ }^{2}$ Conforme Netto, Machado e Oliveira (2002, p. 5), "Pode-se dizer, de uma maneira simplificada, que RV é a forma mais avançada de interface do usuário com o computador até agora disponível. Trata-se de uma interface que simula um ambiente real e permite aos participantes interagirem com o mesmo, permitindo às pessoas visualizarem, manipularem e interagirem com representações extremamente complexas. Ela é um paradigma pelo qual se usa um computador para interagir com algo que não é real, mas que pode ser considerado real enquanto está sendo usado".
} 
social e cultural, de inserção crítica e construtiva de todos na sociedade. Por fim, pode-se afirmar que as pesquisas a respeito de inclusão digital, fundadas inicialmente nos estudos bibliométricos de Notten et al. (2008), "revelam uma lacuna acerca do processo de construção do conhecimento sobre as tecnologias digitais. Trata-se do processo de transformação de indivíduos considerados excluídos digitais para incluídos digitais, uma vez que os estudos exploram a inclusão digital de forma ampla e generalista" (BOLZAN; LÖBLER, 2016, p. 2). Mas, se observarmos de forma mais global, como condição de expressão das diferenças que estão impedidas de participar da vida pública, podemos dizer que há uma espécie de liberdade sobre os limites do próprio corpo com o ciberespaço, no sentido de que por meio dele conseguimos transitar por diferentes estímulos, linguagens, dimensões e mundos.

\section{Educação - um direito de todos}

O debate sobre a educação inclusiva se revela como assunto de preocupação global, cujo eixo projetivo expressa a necessidade de se alcançar uma educação para todos. O conceito de inclusão é relativamente amplo, pois o termo é usado para referenciar as possibilidades de diferentes grupos para usufruírem de saberes comuns na prática social como, por exemplo, a inclusão digital, tema do presente estudo. O termo inclusão é visto como sinônimo para a integração de educandos com deficiência no ensino regular mostrando, assim, a perpetuação da vinculação do conceito com a educação para todos (FERREIRA, 2006). De acordo com Carvalho e Naujorks (2006, p. 2), nota-se que o paradigma de inclusão, "surge como um novo olhar sobre as questões educacionais. Não mais o estudante tem que apresentar uma prontidão para estar na escola, mas a própria escola é chamada a ver que ela pode causar algum empecilho ou dificuldade de integração das diferenças de aprendizagem", afinal, os estudantes são diferentes entre si. Portanto, a escola tem que se preparar para receber todos os educandos, visto que educar é explorar as possibilidades humanas e diminuir suas limitações e deficiências.

Em face deste cenário complexo giram as discussões sobre o processo de inclusão de pessoas com múltiplas deficiências no cotidiano da educação formal. Esse propósito 
faz parte de um conjunto de medidas que têm sido tomadas por parte de estabelecimentos de ensino, sobretudo da rede pública, para ir ao encontro da Lei de Diretrizes e Bases da Educação Nacional, Lei $n^{\circ}$ 9.394/1996, que traz a seguinte observação acerca de uma política de integração.

[...] necessidades educacionais especiais na rede regular de ensino não consiste apenas na permanência física desses alunos junto aos demais educandos, mas representa a ousadia de rever concepções e paradigmas, bem como desenvolver o potencial dessas pessoas, respeitando suas diferenças e atendendo suas deficiências. O respeito e a valorização da diversidade dos alunos exige que a escola defina sua responsabilidade no estabelecimento de relações que possibilitem a criação de espaços inclusivos, bem como procure superar a produção, pela própria escola, de deficiências especiais. (BRASIL, 2001, p. 28)

Em linhas gerais, parte-se do pressuposto de que sujeitos com deficiências podem se beneficiar do compartilhamento do processo pedagógico, contudo, são muitos os conflitos e contradições que têm sido enfrentados na concretização dos ideais de inclusão escolar. Os debates sobre os desafios da inclusão passam pela falta de clareza sobre os conceitos de integração e inclusão. Sugere-se que o ideário de inclusão estaria num plano mais ideológico, ao passo que o conceito de integração indica uma perspectiva mais operacional. Estudiosos da área da educação relatam que a integração seria representada muito mais por uma aproximação física, ao passo que a inclusão pressupõe assegurar a participação do indivíduo ao convívio em grupo (GIMENEZ, 2006). Sob tal ponto de vista, uma das alternativas poderia ser discutir níveis em que ocorra integração ou inclusão. Carvalho (2000) sugere constituir uma difenciação entre quatro distintas formas de integração dos estudantes, a saber: integração física através da diminuição da distância física entre sujeitos sem e com deficiências; integração social através de um vínculo psicológico e social mais próximo, com relações voluntárias e sistematizadas com o intuito de estabelecer vínculos afetivos; integração funcional utilizando artefatos acessíveis a todos; integração societal que busca a democracia nas possibilidades legais e administrativas de tecnologias sociais. Apontam-se ainda alguns avanços, sobretudo, no quesito inclusão, ao citar as várias políticas governamentais adotadas para incentivar o processo de inclusão, tanto na esfera municipal, como na estadual e federal, a saber: 
Contratação de profissionais especializados para atuação nos segmentos de educação especial e educação inclusiva; a reserva de assentos preferenciais em meios de transporte público e atendimentos preferenciais em instituições, tais como bancos e estabelecimentos públicos; a implantação de semáforos com sonorização para portadores de deficiência visual e de telefones para deficentes auditivos e disponibilização de cadeiras de rodas em estabelecimentos públicos; o treinamento de cães guia por meio de projetos especiais da polícia militar; a concessão de escolha prioritária de imóveis em conjuntos habitacionais para sujeitos com deficiência; a concessão de linhas de crédito para a aquisição da casa própria e para a compra de veículos adaptados; a criação de centros de equoterapia; o desenvolvimento e implementação de programas de prevenção e de programas de treinamento específico para profissionais relacionados ao segmento educacional. (GIMENEZ, 2006, on-line)

Debater projetos de inclusão digital de pessoas com múltiplas deficiências, desde os primeiros passos humanos às experiências mais avançadas, torna-se algo muito rudimentar e espinhoso, pois a inclusão é um problema que envolve as dimensões humanas, econômicas, políticas, epistemológicas e culturais. Conforme Lemos (2011, p. 19),

\begin{abstract}
Saber lidar com os novos dispositivos e as redes telemáticas são hoje condições necessárias e imprescindíveis para inclusão social na sociedade da informação[...]. Acho que mais do que dar acesso às tecnologias (uma condição técnica imprescindível e básica para qualquer projeto de inclusão digital), o desafio maior da inclusão cidadã à cultura digital é fazer com que os indivíduos possam produzir conteúdos próprios e distribuí-los livremente [...]. Tanto quanto o capital técnico, os projetos de inclusão digital devem fazer crescer os capitais social, intelectual e cultural. Deve-se ir além dos fatos ou dos artefatos. A inclusão pressupõe autonomia, liberdade e crítica.
\end{abstract}

A autonomia faz parte do processo educativo ao lado da capacidade de (auto)crítica, de ajudar os estudantes a desenvolverem o hábito de fazer leituras e relações no ato de aprender. A capacidade de fazer experiências estimuladoras de decisões frente ao mundo, por meio de atos de recriação educativos, possibilita a abertura ao conhecimento da realidade na ampliação do diálogo com as diferentes compreensões de mundo enquanto amadurecimento do ser, em um processo de busca pela autonomia na interdependência social. É dessa forma que os sujeitos com deficiências requerem um olhar diferenciado de cada educador, a fim de poderem se 
sentir parte integrante do meio escolar e social, pois a inclusão digital é um meio de resgatar socialmente esses indivíduos, pela via da tecnologia assistiva dentro e fora das escolas. Bersch (2008, p. 2) afirma que a TA precisa ser compreendida como "um auxílio que promoverá a ampliação de uma habilidade funcional ou deficitária, ou ainda, que possibilitará a realização de uma função desejada e que se encontra impedida, devido às condições limitantes do sujeito".

Mas não basta ter à mão a tecnologia para conseguir aprender com ela, é preciso que os professores se atualizem no assunto e estejam dispostos a ajudar as crianças a aprender, pelo incentivo educativo, tecnológico, digital e virtual. Mesmo que todos os educandos tenham computadores, se o professor não é capaz de fazer relações educativas do seu trabalho dando sentidos novos às ferramentas, nada pode ser (re)construído coletivamente pois, nesse caso, não basta deixar aprender; é necessário ensinar e estimular os diferentes sentidos. Na perspectiva da educação inclusiva, a TA pode ajudar em diversas metodologias ou mesmo apresentar entraves (tecnopedagogização do ensino), que envolve tanto os estudantes que manifestam limites no convívio social quanto os professores que são contrários às tecnologias e refratários em fazer uso delas para (re)criar e (re)pensar novos sentidos para os estímulos de pesquisa. Conforme Soares (2006, p. 39),

Tecnologia não melhora a essência do que se ensina e sim a forma de transmiti-la. Assumir o emprego de tecnologias educacionais favorece a revisão da prática convencional. Rever atitudes de ensino pelo professor corresponde a ponderar necessidades de inovação da prática como o objeto principal da capacitação ou da formação continuada do professor hoje.

O professor é o articulador destes artefatos tecnológicos com o processo de reelaboração do conhecimento, porque ele é quem coordena o sentido pedagógico. Assim, reduzi-las estritamente ao domínio instrumental é, de certa forma, desumanizar e atrofiar os processos de ensino e de aprendizagem, tendo em vista apenas a manutenção biológica. Mas, qualquer recurso tecnológico tem de fazer sentido e ser incorporado primeiramente pelo professor. Daí que é de extrema importância a abertura do professor, que é capaz de articular as tecnologias para refortificar os estudantes com deficiências a 
viabilizar o desejo e a vontade de transformação, em prol de um processo mais humano de aprender com as tecnologias. Bersch e Tonolli (2006, p. 90) asseguram:

Fazer TA na escola é buscar, com criatividade, uma alternativa para que o aluno realize o que deseja ou precisa. É encontrar uma estratégia para que ele possa "fazer" de outro jeito. É valorizar o seu jeito de fazer e aumentar suas capacidades de ação e interação, a partir de suas habilidades. É conhecer e criar novas alternativas para a comunicação, escrita, mobilidade, leitura, brincadeiras e artes, com a utilização de materiais escolares e pedagógicos especiais. É a utilização do computador como alternativa de escrita, fala e acesso ao texto. É prover meios para que o aluno possa desafiar-se a experimentar e conhecer, permitindo assim que construa individual e coletivamente novos conhecimentos.

A tecnologia é um instrumento capaz de aumentar a motivação dos educandos (mas não é por si um elemento motivador) se a sua utilização estiver inserida num ambiente de aprendizagem desafiador, o que exige um professor atencioso e instrumentos diferenciados para utilizar as tecnologias digitais. Se a proposta de trabalho não for ressignificada constantemente, os estudantes rapidamente perdem a motivação (BRASIL, 1997). Historicamente, as pessoas com deficiências eram privadas dos espaços formais de ensino, pois a deficiência significava a incapacidade para aprender e agir coletivamente. Com isso, muitas pessoas se isolavam da sociedade, porque não se enquadravam nos modelos ou eram vistas como diferentes da maioria, sofrendo segregações e violências nas formas de socialização. Graças às tecnologias digitais, essas mesmas pessoas têm sido e podem ser incluídas na sociedade.

As salas de recursos multifuncionais possuem materiais didáticos, recursos de acessibilidade e equipamentos específicos para o entendimento dos sujeitos, público-alvo da Educação Especial. A tecnologia assistiva é um conjunto de materiais utilizados para ampliar e possibilitar a execução de atividades necessárias às pessoas com múltiplas deficiências. A utilização de atividades lúdicas fomenta a exploração do meio, a apropriação da cultura e a relação com as diferenças humanas, sendo importante a variação de metodologias e materiais, provendo essa maior exploração, investigação do espaço, introdução na imagem e mundo dos jogos. Na perspectiva da educação inclusiva, a TA favorece a participação de sujeitos com deficiências nas diversas atividades do 
cotidiano escolar, desde que vinculadas aos objetivos educacionais. A tecnologia é amplamente considerada nesse processo, mas implica também,

[...] as necessidades de transformação de suas atuais práticas pedagógicas, para que tenham como foco o ensino para todos, propiciando diálogos, possibilitando espaços para cooperação, propostas que atendam às especificidades dos alunos que têm dificuldades ou que não conseguem acompanhar seus colegas de turma. [...] Tecnologia Assistiva torna-se primordial para o êxito da inclusão de pessoas com deficiências na escola regular, pois amplia o campo de possibilidades de concretização de projetos que não tenham meramente uma natureza de reabilitação, mas, sobretudo, o objetivo de promover um encontro da tecnologia educativa como facilitadora dos processos de aprendizagem, visando uma complementação mútua. Notadamente, quanto ao papel crucial da mediação do professor, ressalta-se que a utilização eficaz de qualquer aparato tecnológico pressupõe uma formação adequada dos envolvidos. (RODRIGUES, 2013, p. 15)

Razão pela qual observamos um aumento das pesquisas sobre a utilização da TA, que têm sido relevantes tanto para repensar a inclusão de pessoas com deficiências na escola comum, quanto no sentido de interferir de forma renovada nos modos possíveis (com projetos e estratégias) de se reconhecer a pluralidade e a diversidade cultural na educação.

\section{A problematização da experiência}

Aprender a realidade e levar em consideração não só o que é visto e experimentado, mas o que não está claro e evidente pressupõe um enfoque etnográfico de investigação sobre o qual nos debruçamos nessa experiência de questionar a cultura educacional inclusiva. A pesquisa de cunho etnográfico leva em conta o cotidiano escolar, os contextos e implica uma pesquisa exploratória, cujo propósito é aproximar o pesquisador do problema estudado. Corroborando esse ponto de vista, a pesquisa, de natureza provocadora, tem o propósito de examinar a relação das tecnologias nos processos de ensino e aprendizagem de educandos com múltiplas deficiências. De tal conexão, percebeu-se a relevância do tratamento do tema por meio da pesquisa etnográfica, pois ela facilita um recorte da rotina da sala de aula, em razão do convívio e 
proximidade das diferenças e diversidades culturais dos incluídos/excluídos nas práticas pedagógicas.

Importa também ressaltar ser a etnografia uma metodologia própria para investigar a maneira de viver as experiências das pessoas, as visões de mundo, os sentimentos, ritos, padrões, significados, atitudes, comportamentos e ações. Distintos foram os caminhos de pesquisar da rotina da inclusão digital para a realização desse trabalho. Investigaram-se as informações sobre o uso de tecnologias digitais por crianças com deficiência, provisoriamente, por meio de conversas com as mães das crianças utilizadoras de TA até mesmo em suas casas, mapeando como esses artefatos contribuem para o desenvolvimento de aprendizagens evolutivas.

A pesquisa apresenta e interpreta situações da realidade escolar, fornecendo uma visão detalhada e integrada do objeto de investigação (TA) com o contexto das escolas, além de contribuir para "[...] a descoberta de novos conceitos, novas relações, novas formas de entendimento da realidade" (ANDRÉ, 2008, p. 30). No entendimento de Gil (1999), o caráter exploratório no transcorrer da pesquisa permite esclarecer e modificar concepções para a criação de novas perspectivas, liberando uma maior versatilidade nas análises realizadas, especialmente quando se quer analisar as ideias, atitudes e comportamentos. Sobre o caráter exploratório, Gil (1999) destaca que este possibilita desenvolver, esclarecer e modificar conceitos e ideias para a formulação de abordagens posteriores, pois os participantes da pesquisa podem manifestar diferentes entendimentos, assim como percepções distorcidas ou bifurcadas ao partilhar suas posições. No que tange ao aspecto descritivo, este tem como objetivo registrar, analisar e correlacionar fatos, visando descobri-los, descrevê-los e interpretá-los hermeneuticamente, com o intuito de conhecê-los e aprofundá-los.

Avançou-se para além da observação participante, pois foram realizadas entrevistas semiestruturadas, cujo protocolo foi elaborado a partir de dados empíricos retirados da interação com o campo, visando confirmar o observado e desvendar o sentido de determinados comportamentos, além de pesquisas bibliográficas e conversas informais. Assim, ao examinar a literatura a respeito da inclusão digital na educação de crianças com deficiências, associada à experiência das professoras, projetaram-se os desafios e possibilidades da área, com base na compreensão dos diálogos oriundos da 
rotina escolar e das práticas usuais de professores e estudantes. O cotidiano escolar e os contratempos da rotina da instituição de ensino requerem observação, para serem codificados, com vistas a compreender determinadas dificuldades educacionais, pois ao levar em conta a multiplicidade de interpretações localizadas em determinada situação, atingimos a práxis pedagógica em sua dinamicidade (ANDRÉ, 2008). Sobre o uso do questionário, Gil (1999) compreende que essa técnica de investigação, composta por questões apresentadas por escrito aos sujeitos, tem por intento identificar as opiniões, sentimentos, interesses, expectativas, situações vivenciadas, permitindo ao pesquisador particularidades informais e relevantes.

Neste sentido, foi elaborado um questionário com três questões abertas sobre o tema, aplicado a três educadoras do $3^{\circ}$ ano, no Laboratório de Informática (LABIN) de uma Escola Fundamental de Canoas/RS. Essas professoras foram convidadas e selecionadas para participar do estudo porque representavam o universo de profissionais que atuavam no LABIN da escola. As perguntas que nortearam o estudo foram assim apresentadas: 1 - Quais as práticas pedagógicas usualmente desenvolvidas para incluir alunos com deficiências no mundo virtual? 2 - Você acredita que a inclusão digital estimule os estudantes com deficiências para aprender? Por quê? 3 - Que benefícios tais práticas pedagógicas trazem aos sujeitos com deficiências? As observações foram realizadas nas turmas das mesmas educadoras durante o ano de 2016.

A primeira questão questionava sobre que práticas metodológicas eram desenvolvidas para a inclusão de educandos com deficiências no mundo virtual. Todas as educadoras responderam que o atendimento é feito por agendamento, portanto, o desenvolvimento das atividades é a continuidade do trabalho da sala de aula planejado pelo professor. Desta forma, a mesma prática pensada no planejamento é trabalhada neste espaço, só que de maneira mais atraente, pois o uso do recurso computacional envolve todos os estudantes. Digitar proporciona um contato diferente com a escrita e o estudante fica com mais entusiasmo, vendo e aprendendo a escrita correta. No momento em que aprende a digitar, também aprende a reescrever com as intervenções do professor e dos colegas, especialmente quando os trabalhos são feitos em duplas. Pesquisar na comunidade virtual torna-se uma atividade empolgante e encantadora, pois o mundo virtual é misterioso aos olhos dos educandos, então eles motivam-se nesta 
tarefa.

No laboratório da escola também são feitos trabalhos no PowerPoint. Apresentar suas tarefas nesse programa é gratificante para os processos de reconstrução dos estudantes, pois percebe-se que com a orientação e ajuda constante do professor coordenador eles vêem o resultado dos seus esforços na prática. Nas respostas, impera que ainda há muito o que reconstruir e repensar em termos de materiais tecnológicos para atender os deficientes neste laboratório (LABIN), pois usam-se computadores básicos, com teclados comuns, programas que não contemplam os deficientes visuais e auditivos, ou mesmo com paralisia, sendo que a escola ainda não atende deficientes portadores destas deficiências até o momento.

Nota-se nas ideias recorrentes que as três professoras estão de acordo com a inclusão e constatam os seus benefícios, bem como indicam as dificuldades e as falhas que devem ser revistas. Essa possibilidade vem ao encontro das discussões realizadas até aqui, quando analisamos a questão da inclusão que, para seu enfrentamento, é preciso o trabalho conjunto e o diálogo entre as áreas do conhecimento, como a Sociologia, Antropologia, Psicanálise, Ética, Política, Psicologia, Economia, História, Tecnologia, Comunicação Social, além dos próprios saberes pedagógicos. Outro fato a ser considerado é que a inclusão digital vem a ser apenas um aspecto do processo de educação escolar, que por sua vez também é extremamente complexo e exigente. Em termos educacionais, precisamos reorganizar a participação e a qualificação de professores desde a formação propedêutica, tendo em vista as lacunas em se trabalhar e se reconhecer as diferenças e as singularidades em turmas de trinta, quarenta ou mais sujeitos.

A segunda questão abordava a crença ou não de que a inclusão digital poderia estimular os educandos a aprender. Nesta pergunta, todas as educadoras disseram, por exemplo, que a digitação estimula a (re)escrita, pois não há preocupação com o erro ortográfico e sim com o digitar. Na verdade, é uma dificuldade comum a todos que ainda não digitam. $\mathrm{O}$ aluno se sente incluído neste momento, pois todos são especiais e, nesse sentido, percebe-se um movimento de reconhecimento do outro (descentrado), em prol da valorização das diferenças e do pluralismo cultural. Já, com as experiências no PowerPoint, desenhos no Paint, ocorrem trocas de vivências, novas aprendizagens que 
estimulam o processo de aprender. Conforme essas educadoras, a inclusão digital por meio da digitação faz com que o deficiente sinta-se incluído no processo de mexer com a máquina. Observa-se uma caminhada rumo à participação efetiva, em que os indivíduos tem capacidade não só de usar e manejar esse novo meio, como também de buscar conhecimentos, além de conviver e estabelecer relações que promovam a inserção das múltiplas culturas na rede virtual (SAMPAIO, 2001).

Segundo as educadoras, o visual atrai a atenção e a busca pelo saber através do mundo virtual, ampliando o campo de possibilidades de concretização do ato criativo (por meio da linguagem visual), e permitindo a integração das diversas interpretações desses educandos com as múltiplas visões de mundo e práticas de constituir significados diferentes. A inclusão digital visa democratizar o acesso à informação e auxilia na constituição da cidadania, bem como permite o acesso e a troca de conhecimentos, como forma de praticar a reflexão coletiva. A partir de uma orientação coordenada pelas professoras, todos têm a chance de se comunicar com seus pares por meio dos diversos recursos que a TA proporciona na emergência do reconhecimento. O meio digital ajuda muito os educandos com deficiência, na medida em que estes são estimulados e incentivados a organizar as próprias experiências. Não basta apenas inserir na escola, é necessário incluir para que esses estudantes (re)conheçam os outros e aprendam na convergência das tecnologias a conduzir-se com e por elas.

Cabe aos professores tentar mudar a vida desses estudantes com múltiplas deficiências, oferecendo as condições de possibilidade e relações entre as práticas culturais e esses recursos, abrindo assim novos horizontes para que a inclusão digital se concretize de múltiplos pontos de vista, criando diferentes fluxos que produzem novas sensibilidades, sensações e estímulos constantes. O uso da informática na educação como um exercício contínuo para um prática formadora, tendo em vista a pluralidade humana nas escolas públicas brasileiras, tem se mostrado uma alternativa viável ao desenvolvimento de projetos especiais, oportunizando conhecimentos mútuos entre os sujeitos (com ou sem limitações) do processo educativo de descobertas e produção do conhecimento, no respeito à diversidade, na luta pelo reconhecimento das diferenças e contra as intolerâncias na escola. O uso das ferramentas digitais associa o conhecimento à facilidade de manuseio dos equipamentos, pois os mesmos podem ser contextualizados 
às diferentes realidades e necessidades. Os educadores investigados são unânimes em afirmar que as TDIC para os deficientes são importantes, mas que necessitam de constantes revisões e atualizações voltadas para as diferentes formas de deficiência e necessidades, sempre contingentes, para garantir a inclusão digital. O acesso deve ser compreendido para além do acesso à internet, mas deve surgir como eliminação de barreiras arquitetônicas, de comunicação e de acesso físico a equipamentos e programas adequados, bem como conteúdos e apresentação da informação em formatos alternativos, sensíveis e dinâmicos.

A terceira e última questão buscava compreender os benefícios diretos que as práticas inclusivas com tecnologia digital traziam aos deficientes. Todos os entrevistados deixaram claro que o ambiente digital de aprendizagem ocorre num espaço e tempo cooperativo. O benefício desses momentos está na amplitude de estabelecer trocas entre as diferenças, pois todos podem aprender algo com o outro. O saber individual, quando partilhado, torna-se vivaz e significativo nas relações entre educadores e educandos, inseparáveis da prática cotidiana. Trabalhar em parceria, executando tarefas individuais e coletivas cria um movimento instigante rumo ao processo de ensino e de aprendizagem, que é extremamente benéfico às diversidades e às deficiências, culminando na produção de novos saberes, num pensar e agir coletivo. Nesse contexto, destaca-se que trabalhar a inclusão em meio à cultura digital é prazeroso e muito mais interessante para desenvolver a autenticidade dos educandos, sentindo-se assim parte integrante do processo, visto que o meio digital oferece caminhos desconhecidos de acesso a todos, sejam crianças com diferentes tipos de deficiência ou não. Essas educadoras sinalizam que as ações ligadas à integração do deficiente ao mundo digital ocorrem de forma cooperativa, e que o processo inclusivo pode significar uma verdadeira revolução educacional que envolve o surgimento de uma escola humanizada, diferente, aberta, comunitária, solidária e democrática, em que a multiplicidade conduz a ultrapassagem dos limites da integração e alcançam a inclusão. Os educadores indicam que a inclusão digital permite que os estudantes se apoderem dos recursos digitais, atribuindo uma nova forma de aprendizagem e interação com o mundo, de diminuição das barreiras sociais e em constante reelaboração na multiplicidade das diferenças e dos diferentes espaços de formação. 
A socialização do saber virtual viabiliza aos estudantes deficientes, mais um meio de inclusão social. Quando o professor que trabalha com deficientes tem formação específica e permanente na área, ele consegue caminhar para formas experimentais e plurais de conhecer, colaborando com os educandos no desenvolvimento e estímulo do raciocínio e da possibilidade de transformação de saberes sensíveis aos contextos. Concretamente, as respostas das educadoras investigadas provam que o processo inclusivo pode significar uma verdadeira revolução educacional e envolve o descortinar de uma escola sensível às necessidades e aos contextos, de forma aberta, comunitária, solidária e democrática, em quea multiplicidade leva a ultrapassar os limites particulares na integração e inclusão de todos. Portanto, a discussão sobre a integração dos educandos com deficiências no ensino regular é o caminho para se atingir a inclusão social, constituindo-se uma meta deste século. Isso pressupõe que o sistema educacional, como um todo, precisa assumir a responsabilidade política de desenvolver uma Educação Especial, ancorada no respeito e na consideração com o diferente, aberta à experimentação das diversidades e mudanças culturais pungentes.

\section{Considerações finais}

Compreendemos que a escola precisa estar preparada para reconhecer as particularidades e necessidades de todos, tendo em vista que a educação é um direito social e um ato político, que precisa de uma (auto)crítica permanente para superar as mutilações generalizantes inscritas no ensinar e no aprender. Dessa forma, indicamos que as TDIC e TA podem auxiliar na promoção de novas formas de aprender cooperativo, com os diferentes ritmos e estilos de aprendizagem, com novos modos de (re)construção de saberes e interação com os objetos. Com esses recursos, os sujeitos que apresentam deficiências têm a possibilidade de expandir suas capacidades, o que suscita a autonomia humana para os saberes e articula novos desafios às diferenças e à construção de projetos comuns, para dar resposta à diversidade cultural.

Conforme as observações e as entrevistas coletadas no percurso da pesquisa, o desafio da educação brasileira passa por políticas de inclusão educacional de promoção do acesso às tecnologias, mas igualmente passa pela abertura a novos olhares e percepções sobre as diferentes necessidades dos educandos nas escolas, para 
disponibilizar condições efetivas de acesso ao mundo digital, sem nenhum tipo de discriminação ou segregação. Na tentativa de ultrapassar os contratempos que impedem a expressão de diferentes aprendizagens e a participação com igualdade de oportunidades, as três professoras entrevistadas articulam suas ações pedagógicas aos valores, experiências cotidianas e estão sempre atentas para estimular e valorizar as diferenças como forma de inclusão e enriquecimento do processo educacional. As situações desafiadoras de inclusão digital de educandos com múltiplas deficiências nos processos educacionais podem colaborar na construção de identidades, na medida em que eles se percebem enquanto sujeitos produtores de culturas por meio das tecnologias digitais, que podem agir de modo diferente em relação à construção das próprias aprendizagens e com as diferenças dos outros.

Ao falarmos de uma cultura do diálogo com as transformações tecnológicas que a sociedade produz, a pesquisa possibilitou ainda um processo de rever as práticas culturais da escola, além de destacar o papel das TDIC e da TA para retroalimentar e superar as barreiras dos processos inclusivos nas classes comuns do ensino regular. A partir da ampliação de programas para a formação de professores, adequação arquitetônica dos prédios escolares para acessibilidade e a organização de recursos técnicos e de serviços incentivadores da mobilidade pedagógica pelas comunicações digitais, a inclusão digital poderá transformar-se em uma realidade e oportunidade para estimular aprendizagens evolutivas nas escolas. De acordo com essa pesquisa, as educadoras investigadas revelaram que a inclusão tecnológica e digital tem se mostrado uma excelente ferramenta à aprendizagem, convivência, valorização do outro, respeito e socialização entre os três diferentes grupos escolares. Concluímos, com base na experiência descrita, que a inclusão digital é certamente mais uma perspectiva capaz de resgatar pela via educacional os educandos com múltiplas deficiências, preparando-os para o convívio social com o mundo virtual e tecnológico, com tolerância às diversidades da condição humana. Estudos recentes sobre a inclusão social revelam que o desenvolvimento econômico determina os limites da inclusão e exclusão digital, por isso, "mais do que um direito, precisa ser uma condição para novas aprendizagens sociais, que celebra o reconhecimento da diversidade linguística para o desenvolvimento coletivo" (CONTE; HABOWSKI; RIOS, 2019, p. 35). 


\section{Referências}

ANDRÉ, Marli Eliza Dalmazo Afonso de. Etnografia da prática escolar. Campinas: Papirus, 2008.

BERSCH, Rita; TONOLLI, José Carlos. Introdução ao Conceito de Tecnologia Assistiva e Modelos de Abordagem da Deficiência. CEDI - Centro Especializado em Desenvolvimento Infantil. Porto Alegre, 2006. Disponível em: <http://www.bengalalegal.com/tecnologiaassistiva>. Acesso em: 02 fev. 2016.

BERSCH, Rita. Introdução às Tecnologias Assistivas. CEDI - Centro Especializado em Desenvolvimento Infantil. Porto Alegre, 2008.

BOLZAN, Larissa Medianeira; LÖBLER, Mauri Leodir. Socialização e afetividade no processo de inclusão digital: um estudo etnográfico. Organ. Soc., vol. 23, n. 76, Salvador Jan./Mar. 2016, p.130-149. Disponível em:

<http://www.scielo.br/scielo.php?script=sci_arttext\&pid=S1984

92302016000100130\&lng=en\&nrm=iso\&tlng=pt >. Acesso em: 29 nov. 2017.

\section{BRASIL. Política Nacional de Educação Especial na Perspectiva da Educação Inclusiva.}

Secretaria de Educação Especial. Legislação Específica. Documentos Internacionais, Brasília, 2007. Disponível em:

http://portal.mec.gov.br/index.php?option=com_docman\&view=download\&alias=16690politica-nacional-de-educacao-especial-na-perspectiva-da-educacao-inclusiva05122014\&Itemid=30192 Acesso em: 12 set. 2017.

BRASIL. Sala de Recursos Multifuncionais: espaços para o Atendimento Educacional Especializado. Brasília: MEC/SEESP, 2007a.

BRASIL. Secretaria de Educação Fundamental. Parâmetros Curriculares Nacionais: introdução aos parâmetros curriculares nacionais. Secretaria de Educação Fundamental. Brasília: MEC/SEF, 1997. Disponível em:

http://portal.mec.gov.br/seb/arquivos/pdf/livro01.pdf Acesso em: 20 abr. 2017.

CARVALHO, Renata Corcini; NAUJORKS, Maria Inês. Representações sociais: dos modelos de deficiências aleitura de paradigmas educacionais. Revista Educação Especial, n. 27, 2006. Disponível em:

<https://periodicos.ufsm.br/educacaoespecial/article/view/4345/2555>. Acesso em: 29 nov. 2016.

CARVALHO, Rosita Edler. Removendo Barreiras para a Aprendizagem. Educação Inclusiva. Porto Alegre: Mediação, 2000.

CONTE, Elaine; HABOWSKI, Adilson Cristiano; RIOS, Míriam Benites. Ressonâncias das tecnologias digitais na educação. Revista Ibero-Americana de Estudos em Educação, Araraquara, v. 14, p. 31-45, 2019. DOI: 10.21723/riaee.v14i1.11110 
EUSTAT. Educação em tecnologias de apoio para utilizadores finais: linhas de orientação para formadores. 1999. Disponível em:

<http://www.siva.it/research/eustat/eustgupt.html>. Acesso em: 26 nov. 2016.

FERREIRA, Windyz B. Inclusão X exclusão no Brasil: reflexões sobre a formação docente dez anos após Salamanca. In: RODRIGUES, David (Org.). Inclusão e educação: doze olhares sobre a educação inclusiva. São Paulo: Summus, 2006.

GADAMER, Hans-Georg. Verdade e Método I. Traços fundamentais de uma hermenêutica filosófica. São Paulo: Editora Universitária São Francisco, 2005.

GIL, Antônio Carlos. Métodos e técnicas de pesquisa social. 5. ed. São Paulo: Atlas, 1999.

GIMENEZ, Roberto. A inclusão de indivíduos portadores de necessidades especiais nas aulas regulares de educação física: repensando sobre a prática. Revista Digital. Buenos Aires, año 11, n. 98, Julio de 2006. Disponível em:

<http://www.efdeportes.com/efd98/inclusao.htm> Acesso em: 17 set. 2017.

HERMANN, Nádia. Hermenêutica e Educação. Rio de Janeiro: DP\&A, 2003.

LEMOS, André. Prefácio. In: PRETTO, Nelson; BONILLA, Maria Helena (Orgs.). Inclusão digital: polêmica contemporânea. Salvador: EDUFBA, 2011. v. 2. 188 p. Disponível em: <http://www.repositorio.ufba.br:8080/ri/bitstream/ri/4859/1/repositorioInclusao\%2odigital-polemica-final.pdf> Acesso em: 9 mai. 2017.

LEVY, Gisele C.T.M.; FACION, José R.. O papel do professor na educação inclusiva. In. FACION, José Raimundo. Inclusão escolar e suas implicações. 2. ed. Curitiba: Ibepex, 2009. pp. 139-167.

NETTO, Antônio Valério; MACHADO, Liliane dos Santos; OLIVEIRA, Maria Cristina Ferreira de. Realidade Virtual - Definições, Dispositivos e Aplicações. 2002. Disponível em: <http://www.di.ufpb.br/liliane/publicacoes/2002_reic.pdf> Acesso em: 09 mai. 2017.

RODRIGUES, Maria Euzimar Nunes. Avaliação da tecnologia assistiva na sala de recursos multifuncionais. 2013. 111f. Dissertação (Mestrado em Educação) - Universidade Federal do Ceará, Fortaleza, 2013. Disponível em:

<http://www.repositorio.ufc.br/bitstream/riufc/6017/1/2013-DIS-MENRODRIGUES.pdf>. Acesso em: 29 nov. 2017.

SAMPAIO, Jorge Thadeu. TCls, Democracia, Sampa.org e Inclusão Digital. 2001. Disponível em: <http://www.sampa.org>. Acesso em: 07 abr. 2017.

SOARES, Suely Galli. Ensino Superior e tecnologias educacionais. In: SOARES, Suely Galli (Org.). Cultura do desafio: gestão de tecnologias de informação e comunicação no ensino superior. São Paulo: Alínea, 2006.

SOUZA, Carlos Henrique Medeiros; GOMES, Maria Lúcia Moreira. Educação e 
Ciberespaço. Brasília: Usina das Letras, 2008.

Recebido em: 02/07/2017

Revisões requeridas em: 07/08/2017

Aprovado em: 31/10/2017

Universidade do Estado de Santa Catarina - UDESC Programa de Pós-Graduação em Educação - PPGE

Revista Linhas

Volume 20 - Número 42 - Ano 2019

revistalinhas@gmail.com 